\section{References}

Bruggen, P. \& O'BrIEN, C. (1987) Helping Families Systems, residential and agency responsibility. London: Faber \& Faber.

DenNeR, B. \& Halprin, F. (1974) Measuring consumer satisfaction in a community outpost. American Journal of Community Psychology, 2, 13-22.

Hildebrand, J., Jenkins, J., Carter, D. \& Lask, B. (1981) The introduction of a full family orientation in a child psychiatric in-patient unit. Journal of Family Therapy, 3, 139-152.
LaBarbera, J., Martin, J., Dozier, E. (1982) Residential treatment of males: the influential role of parental attitudes. Journal of the American Academy of Child Psychiatry, 21, 286-290.

PARK, M. \& LikIERMan, H. (1990) Collingham Gardens Child and Family Psychiatry Unit First Year Evaluation Report. Riverside Health Authority.

Wels, P. (1989) Why admit to a bed? Disposal of 1,000 referrals to a Regional Adolescent Service. Psychiatric Bulletin, 13, 342-344.

\title{
Whither the disturbed patient: a study of regional secure unit referrals from two health districts
}

\author{
George J. Lodge, Consultant Psychiatrist, Roundway Hospital, Devizes, \\ Wiltshire SN10 5DS
}

Roundway Hospital provides all rehabilitation and continuing care (rehab) beds for the Swindon Health District (Swindon), population 245,000; the Wiltshire sector of the Bath Health District (Wilts) population 200,000; and the Bath City sector of the Bath Health District (Bath), population 85,000.

Like other similar hospitals it has seen enormous reductions in bed use. Recently, however, managerial pressure to reduce bed numbers to finance service developments has overtaken clinical initiative. These reductions have been accompanied by a dramatic increase in the two districts' use of the Wessex Regiona Secure Unit (RSU) to deal with violent disturbed patients from one admission in 1981 to ten during 1989.

Might this apparent increasing difficulty in coping with disturbed violent patients be linked with the shrinking and threatened closure of the asylum?

\section{The shrinking asylum}

A first look at the statistics showed that early in the decade, Swindon was the major referrer. This might be accounted for by higher intrinsic rates of disturbance (Swindon is a rapidly expanding town) or by insufficient acute bed provision. Swindon's provision in 1981 was 0.26 beds/ 1000 population c.f. $0.35 / 1000$ and $0.33 / 1000$ for Wilts and Bath respectively. By 1989 the acute bed provision for the three areas was nearer equity: $0.25,0.30$ and $0.25 / 1000$ respectively and the ratio of admissions to the RSU (4:4:2) much closer to population ratios. When, however, the correlation between RSU admissions and changes in acute bed provision was calculated for the years 1981-1989, this proved non-significant: $R=-0.16$.

New and old long-stay rehab beds have reduced from $0.69,0.7$ and 0.2 per 1000 for Swindon, Wilts and Bath in 1981 to $0.18,0.21$ and 0.15 per 1000 respectively in 1989 . There is a highly significant correlation between RSU admissions and reductions in these beds: $R=0.93 ; P<0.001$. The correlation is slightly weaker with percentage annual rehab bed reductions: $R=0.86 ; P<0.01$. Other figures (total institution size and combined acute and rehab bed reduction) also show significant correlations, though less strong.

\section{Underlying factors}

One reason for increased use of the RSU might be an impairment of the institution's capacity to admit because of too rapid a rate of change. If so, then one might expect that increasing numbers of referrals might come direct from DGHs, courts, prisons and the community. This proved to be the case, with a highly significant correlation between referrals from these sources and overall referrals: $R=0.94$; $P<0.001$

Were we referring less disturbed patients? If so, then length of stay at the RSU might be shorter. 
There is a suggestive though non-significant correlation between referral rates and length of stay: $\mathrm{R}=-0.48$.

Locked ward policy has not changed throughout the study period.

That lower numbers of male staff might reduce our ability to cope could not be confirmed or refuted. Personnel figures on the male/female ratio among nursing staff were not available though the male/ female ratio for student nurse recruitment showed no significant correlations.

Twenty-nine qualified staff from acute and rehab areas returned a questionnaire scoring ten possible relevant factors on a five point scale. The five most highly ranked factors, in order were:

(1) insufficient staff on ward

(2) violent patients adversely affect ward environment

(3) insufficient back-up in hospital

(4) insufficient male staff

(5) insufficient training in handling violent patients.

All these were ranked significantly higher, $P<0.05$ (Wilcoxon's ranked pairs test) than the other five responses:

(6) staff willingness to risk personal violence

(7) inadequate medical support

(8) reaction to management attitudes

(9) insufficient beds

(10) some patients need to be away from their families.

The only significant within group difference was between (6) and (10).

The second highest ranked of these responses highlights, I believe, one reason why the loss of rehab beds so significantly affects the ability of a service to cope with difficult and violent patients. Such patients seriously disrupt an acute ward environment. Unable to admit to rehab beds, we have nowhere for these patients to go.

\section{What is the future?}

Should we send all difficult patients to specialist regional or sub-regional centres or plan and staff local units so that they can cope? Because of loss of contact with families, loss of continuity of care, difficulty of rehabilitating patients back from a remote unit and the loss of expertise in dealing with such cases local units would suffer. I would not favour the first solution. If, however, we want local services I suggest we need to provide the following:

(1) a hospital of sufficient size to summon adequate staff in an emergency, probably a hospital with 4-5 ward units to allow 5-6 staff to be assembled in one place in an emergency at night

(2) at least one ward with sufficient trained staff to provide continuing control of potentially aggressive patients throughout 24 hours

(3) nurses adequately trained in the techniques of control and restraint and defusing and avoiding potential violence

(4) recruitment of some nurses of reasonable physical presence

(5) design and siting of units allowing patients adequate physical space and room to roam

(6) a secure room

(7) stability in size and function

(8) the asylum function should be valued.

Our Victorian asylums have been much denigrated but perhaps this is because we have forgotten the philanthropy of our forefathers. Roundway Hospital's original 12 wards were intended for 250 patients. Even now its remaining 12 wards contain around 300 patients. A valid criticism is our failure to provide an acceptable standard of care and environment. The King's Fund Consensus Conference (King's Fund, 1987) brought to national recognition the continuing requirement for an asylum function. The purpose of the asylum is a noble one, "A place of refuge ... an institution for the shelter and support of afflicted persons especially lunatics"' (Concise Oxford Dictionary). We should seek to provide asylum to those in need but to a standard and in an environment we would accept ourselves close to patients' families and communities of origin.

\section{Reference}

KING's Fund (1987) The Need for Asylum in Society for the Mentally Ill or Infirm. London: King's Fund Centre. 